Available online at http://journal.stkip-andi-matappa.ac.id/index.php/histogram/index

Histogram: Jurnal Pendidikan Matematika 4(2)., 2020, 590 - 600

\title{
PENGGUNAAN SOFTWARE GEOGEBRA PADA MATAKULIAH MATEMATIKA I MATERI INTEGRAL
}

\begin{tabular}{c} 
Amiruddin', Esterina Natalia Paindan $^{2}$ \\
$1,2)$ STT Migas Balikpapan \\
* Corresponding Author. Email: amir_bppn@yahoo.com \\
Received: 10 Agustus 2020; Revised: 15 September 2020; Accepted: 30 September 2020 \\
\hline
\end{tabular}

\section{ABSTRAK}

Penelitian ini bertujuan untuk mengetahui peningkatan pemahaman matematis mahasiswa STT Migas Balikpapan pada matakuliah matematika I materi integral. Jenis penelitian ini adalah penelitian eksperimen, dengan populasi mahasiswa STT Migas Balikpapan yang mengambil matakuliah matematika I pada semester I, dan sampel dalam penelitian ini diperoleh satu kelas dengan menggunakan teknik purposive sampling. Instrumen penelitian ini berupa tes uraian untuk mengukur tingkat pemahaman matematis materi integral. Desain dalam penelitian ini adalah quasi eksperimen dengan desain one group pretest-posttest data yang diperoleh dianalisis dengan menggunakan N-Gain Score. Berdasarkan hasil penelitian nilai rata-rata pretest 38,33 setelah dilakukan pengunaan geogebra diperoleh nilai rata-rata postest 74,17, dengan nilai $N$-Gain 0,62 dengan kategori sedang dan untuk tafsiran keefektifan $N$-Gain sebesar 62\% dengan kata lain penggunan geogebra dikategorikan cukup efektif, sehingga penelitian ini dapat disimpulkan bahwa penggunaan geogebra dapat meningkatkan kemampuan pemahaman matematis mahasiswa materi integral.

Kata kunci: Media, Pembelajaran, Geogebra, Pemahaman, Integral

\section{ABSTRACT}

The research which aimed to discover the enhancement mathemtical understanding of STT Migas Balikpapan students in the integral material mathematics I course. The research was experiment research. The population was all of the students of STT Migas Balikpapan who take mathematics I in the first semester, the samples were selected one class by conducting purposive sampling techniques. The research instrument is a test description to measure the level of mathematical understanding of integral material. The design in this research was a quasi experimental design with one group pretest-posttest, the data obtained were anlyzed using the N-Gain Score. Based on the results of the research, the pretest average value was 38.33, after using geogebra the posttest average score was 74,17, with an $\mathrm{N}$-Gain value of 0.62 in the medium category and for the interpretation of the effectiveness of $N$-Gain it was $62 \%$ in other word geogebra is categorized as quite effective, so that this research can be concluded that the use of geogebra can improve students mathematical understanding of integral

Keywords: Media, Learning, Geogebra, Understanding, Integral

How to Cite: Amiruddin., \& Paindan, E, N. (2020). Penggunaan Software Geogebra Pada Matakuliah Matematika I Materi Integral. Histogram: Jurnal Pendidikan Matematika, 4(2), 590 - 600, doi: http://dx.doi.org/10.31100/histogram.v4i2.806

Permalink/DOI: http://dx.doi.org/10.31100/histogram.v4i2.806

\section{PENDAHULUAN}

Pesatnya perkembangan teknologi komputer saat ini, manfaat komputer telah dirasakan di berbagai sektor kehidupan. Dalam sektor pendidikan misalnya, pemanfaatan komputer sudah berkembang tidak hanya sebagai alat yang hanya dipergunakan untuk urusan keadministrasian saja, melainkan juga dimungkinkan untuk digunakan sebagai salah satu alternatif dalam pemilihan media pembelajaran (Nur, 2016).

Copyright (C) 2020, THE AUTHOR (S). This article distributed under the CC-BY-SA-license. 


\section{Histogram: Jurnal Pendidikan Matematika, 4 (2), 2020 - 591 Amiruddin' $^{1}$, Esterina Natalia Paindan ${ }^{2}$}

Beberapa software matematika salah satunya yaitu Geogebra. Geogebra adalah program dinamis yang dengan beragam fasilitasnya dapat dimanfaatkan sebagai media pembelajaran matematika untuk mendemonstrasikan atau memvisualisasikan konsepkonsep matematis serta sebagai alat bantu untuk mengkonstruksikan konsep-konsep matematis (Tanzimah, 2019).

Di perguruan tinggi khususnya pada jurusan-jurusan eksak diberikan matakuliah yang menyangkut matematika, salah satunya matakuliah Matematika I yang diberikan pada mahasiswa semester awal. Mata kuliah Matematika I merupakan mata kuliah wajib yang mesti dikuasai mahasiswa tingkat pertama untuk memberikan landasan pengajaran matematika yang lebih lanjut serta memberikan landasan penerapannya dalam memecahkan masalah nyata atau sebagai penunjang untuk mata kuliah lain, adapun materi pada matakuliah Matematika I salah satunya adalah materi Integral. (Siagian, 2020) Integral merupakan bentuk operasi matematika yang menjadi kebalikan (invers) dari operasi turunan dan limit dari jumlah atau suatu luas daerah tertentu. Berdsarkan pengertian tersebut untuk menentukan suatu luasan daerah diperlukan suatu gambaran secara visual, agar mahasiswa dapat menginterpretasikannya.

NCTM (Hikmah, 2017) menyebutkan bahwa aspek penting dalam pembelajaran matematika adalah kemampuan pemahaman matematis. Berdasarkan data TIMSS (Putra et al., 2018) menunjukkan bahwa lemahnya kemampuan pemahaman matematis dalam menyelesaikan masalah soal-soal tidak rutin. Beberapa faktor yang mempengaruhi kemampuan pemahaman matematis, seperti model pembelajaran, tingkat perkembangan kognitif siswa, dan cara belajar siswa. Kemampuan pemahaman Anderson et al. (Syarifah, 2017) terdiri dari tujuh jenis, yaitu interpreting (menginterpretasikan), exemplifying (memberikan contoh), classifying (mengklasifikasikan), summarizing (meringkas), inferring (menyimpulkan), comparing (membandingkan), dan explaining (menjelaskan). Sedangkan indikator pemahaman konsep menurut kurikulum 2006 (Sari et al., 2016) yaitu menyatakan ulang sebuah konsep, mengklasifikasikan objek-objek menurut sifat-sifat tertentu (sesuai dengan konsepnya), memberikan contoh dan non contoh dari konsep, menyajikan konsep dalam berbagai bentuk representasi matematis, mengembangkan syarat perlu atau syarat cukup suatu konsep, menggunakan, memanfaatkan, dan memilih prosedur atau operasi tertentu, dan mengaplikasikan konsep atau algoritma pemecahan masalah. Dari beberapa pendapat tersebut, dapat disimpulkan bahwa pemahaman matematis adalah pengetahuan tentang konsep, prinsip, prosedur, dan kemampuan menggunakan strategi penyelesaian terhadap suatu masalah yang disajikan. Seseorang yang telah memiliki 


\section{Histogram: Jurnal Pendidikan Matematika, 4 (2), 2020 - 592 Amiruddin', Esterina Natalia Paindan²}

kemampuan pemahaman matematis berarti orang tersebut telah mengetahui apa yang dipelajarinya, langkah-langkah yang dilakukan, dapat menggunakan matematika dalam konteks matematika dan di luar konteks matematika.

Berdasarkan pemaparan tersebut dapat dihubungkan antara matakuliah Matematika I pada materi integral dengan software geogebra yaitu dengan menggunakan sebuah media pembelajaran yang berbasis teknologi untuk menunjang pembelajaran serta membantu mahasiswa yang mengambil mata kuliah Matematika I materi integral dalam hal mendemonstrasikan dan memvisualkan konsep-konsep matematis untuk meningkatkan pemahaman matematis.

Berdasarkan identifikasi masalah, maka pada penelitian ini hanya dibatasi dengan penggunaan software Geogebra pada materi integral yang diperuntukkan kepada mahasiswa yang mengambil mata kuliah Matematika I. Sesuai dengan latar belakang maka dibangun rumusan masalah sebagai berikut: "Apakah penggunaan software Geogebra dapat meningkatkan pemahaman matematis pada matakuliah Matematika I materi integral?". Penelitian ini diharapkan dapat bermanfaat sebagai berikut: (a) Sebagai salah satu sumber belajar dalam upaya meningkatkan kemampuan mahasiswa di bidang matematika khususnya dalam mendemonstrasikan dan memvisualkan konsep-konsep matematis ke dalam masalah nyata pada materi integral. (b) Sebagai kontribusi untuk membentuk jaminan mutu pendidikan tinggi dalam bidang matematika.

\section{METODE PENELITIAN}

Penelitian ini dilakukan di STT Migas Balikpapan Tahun Ajaran 2020/2021. Penelitian ini dikategorikan ke dalam penelitian eksperimen yaitu penelitian jenis Quasi Experimental (ekperimen semu). Tujuan eksperimen semu adalah untuk memperoleh informasi yang merupakan yang sebenarnya dalam keadaan yang tidak memungkinkan untuk mengontrol atau memanipulasikan semua varibel yang relevan. Populasi dalam penelitian ini adalah mahasiswa STT Migas Balikpapan tahun ajaran 2020/2021 yang mengambil matakuliah matematika I pada semester I, sedangkan sampel dalam penelitian ini diperoleh satu kelas dengan menggunakan purposive sampling . Rancangan penelitian yang digunakan adalah The One Group Pretest-Posttest design, seperti pada Tabel 1.

Tabel 1. Rancangan Penelitian

\begin{tabular}{ccc}
\hline Pre Test & Perlakuan & Post Test \\
\hline T1 & $\mathrm{X}$ & T2 \\
\hline
\end{tabular}

Sumber: Sugiyono, Tahun: 2011 


\section{Histogram: Jurnal Pendidikan Matematika, 4 (2), 2020 - 593}

Amiruddin', Esterina Natalia Paindan²

Keterangan:

T1 : Tes awal sebelum perlakuan

$\mathrm{X}$ : Perlakuan dengan menggunakan software geogebra

T2 : Tes akhir setelah perlakuan

Penelitian ini melibatkan variabel bebas dan varibel terikat. Adapun variabel bebasnya adalah media pembelajaran geogebra untuk materi integral pada matakuliah matematika I. Sedangkan variabel terikatnya adalah kemampuan pemahaman matematis materi integral pada matakuliah matematika I.

Untuk mendapatkan data yang akan diperlukan dalam penelitian ini, digunakan jenis instrumen yaitu: tes kemampuan pemahaman matematis. Tes kemampuan pemahaman matematis berbentuk tes uraian. Sebelum digunakan, soal tes tersebut dilakukan uji validitas. Uji validitas dilakukan melalui pertimbangan para ahli tentang isi dan konstruk dari soal tes serta diujicobakan kepada mahasiswa yang bukan kelas sampel penelitian sebagai validitas empirik.

Adapun teknik analisis data dalam penelitian ini yaitu: Data kemampuan pemahaman matematis diperoleh dari hasil pretest dan postest dianalisis untuk mengetahui besarnya peningkatan kemampuan pemahaman matematis. Besarnya peningkatan sebelum dan sesudah pembelajaran dihitung dengan rumus gain ternormalisasi, Hake R.R (Yensy, 2020) yaitu:

$$
g=\frac{S_{\text {pos }}-S_{\text {pre }}}{S_{\text {mak }}-S_{\text {pre }}}
$$

Keterangan:

$\begin{array}{lll}\text { g } & : & \text { Gain ternormalisasi } \\ \text { Spre } & : & \text { Skor pretest } \\ \text { Spos } & : & \text { Skor posttest } \\ \text { Smak } & : & \text { Skor maksimum ideal }\end{array}$

Untuk interpretasi gain ternormalisasi terlihat pada tabel 2 berikut:

Tabel 2. Klasisfikasi Gain ternormalisasi

\begin{tabular}{cc}
\hline Besar $\boldsymbol{g}$ & Interpretasi \\
\hline $\mathrm{g}<0,3$ & Rendah \\
$0,3 \leq \mathrm{g}<0,7$ & Sedang \\
$\mathrm{g} \geq 0,7$ & Tinggi \\
\hline Sumber: Hake, R.R dalam Yensy, Tahun: 2020
\end{tabular}




\section{Histogram: Jurnal Pendidikan Matematika, 4 (2), 2020 - 594 \\ Amiruddin', Esterina Natalia Paindan²}

Adapun untuk tafsiran efektivitas dari Gain ternormalisasi terlihat pada tabel 3 berikut ini:

Tabel 3. Kategori Keefektifan N-Gain

\begin{tabular}{cc}
\hline Persentase & Tafsiran \\
\hline$<40,00$ & Tidak Efektif \\
$40,00-55,99$ & Kurang Efektif \\
$56,00-75,00$ & Cukup Efektif \\
$>75,00$ & Efektif \\
\hline Sumber: Hake, R.R dalam Yensy, Tahun: 2020
\end{tabular}

\section{HASIL DAN PEMBAHASAN}

\section{A. Hasil Penelitian}

Berdasarkan penelitian yang telah dilakukan, diperoleh nilai n-gain dari masingmasing mahasiswa untuk melihat peningkatan kemampuan pemahaman matematisnya. Dari data diperoleh deskripsi data kemampuan pemahaman matematisnya sebagai berikut:

Tabel 4. Deskripsi Data Kemampuan Matematis

\begin{tabular}{cccccc}
\hline $\begin{array}{c}\text { Kemampuan } \\
\text { Matematis }\end{array}$ & N & Min & Maximum & Rata-Rata & $\begin{array}{c}\text { Simpangan } \\
\text { Baku }\end{array}$ \\
\hline Pre Test & 36 & 20 & 80 & 38,330 & 18,890 \\
\hline Post Test & 36 & 40 & 100 & 74,170 & 15,380 \\
\hline N Gain & 36 & 0,250 & 1 & 0,620 & \\
\hline N Gain (Persen) & & $25 \%$ & $100 \%$ & $62 \%$ & \\
\hline
\end{tabular}

(Sumber: Data Primer, Tahun: 2020)

Berdasarkan hasil perhitungan yang disajikan pada Tabel 4, dengan hasil pretest dan postes kemampuan pemahaman matematis dengan menggunakan software geogebra sebagai perlakuan dalam penelitian ini, dari 36 mahasiswa diperoleh besarnya simpangan baku untuk skor pretest adalah 18,890 sedangkan untuk skor postest adalah 15,380, dari data tersebut terlihat bahwa penyebaran data pretest lebih besar daripada data postest, dengan kata lain bahwa skor postest data lebih mendekati nilai rata-rata. Pada nilai ratarata kemampuan matematis mahasiswa untuk pretest adalah 38,333 sedangkan untuk postest adalah 74,170 dari skor idealnya adalah 100 , ini menunjukkan bahwa rata-rata kemampuan matematis postest lebih baik dari pretest, artinya ada kenaikan sebesar 35,830 dari nilai rata-rata. Berdasarkan rata-rata N-Gain diperoleh nilai sebesar 0,620 dengan kategori sedang yaitu berada pada kisaran 0,3 sampai dengan 0,7, ini menandakan bahwa kenaikan kemampuan pemahaman matematis yang dialami mahasiswa tergolong sedang, adapun untuk kefektifan dari penggunaan geogebra ditunjukkan dengan nilai persentase N- 


\section{Histogram: Jurnal Pendidikan Matematika, 4 (2), 2020 - 595}

Amiruddin', Esterina Natalia Paindan²

Gain ternormalisasi diperoleh sebesar 62\% yang menandakan bahwa penggunaan software geogebra untuk materi integral pada matakuliah matematika I ditafsirkan cukup efektif.

\section{B. Pembahasan}

Penggunaan software komputer dalam pembelajaran matematika saat ini sangat berkembang salah satunya adalah Geogebra. Di perguruan tinggi khususnya pada jurusanjurusan eksak diberikan matakuliah matematika yang merupakan matakuliah wajib yang mesti dikuasai mahasiswa tingkat pertama untuk memberikan landasan penerapannya dalam memecahkan masalah nyata atau sebagai penunjang untuk matakuliah lain, adapun salah satu materi yang diajarkan adalah materi integral. Pada software geogebra menyajikan penyelesaian dalam bentuk integral sehingga mahasiswa dapat terbantu dalam mendemonstrasikan dan memvisualkan konsep-konsep matematika untuk dipahami, dan juga sebagai alat bantu bagi mahasiswa untuk menemukan suatu penyelesaian matematis .

Adapun penggunaan geogebra pada materi integral dapat disajikan sebagai berikut:

1. Menentukan nilai integral tak tentu dari suatu fungsi.

Contoh : Tentukan nilai dari $\int\left(3 x^{2}+4 x-5\right) d x$. Maka penggunaanya dengan geogebra tampak pada gambar berikut ini

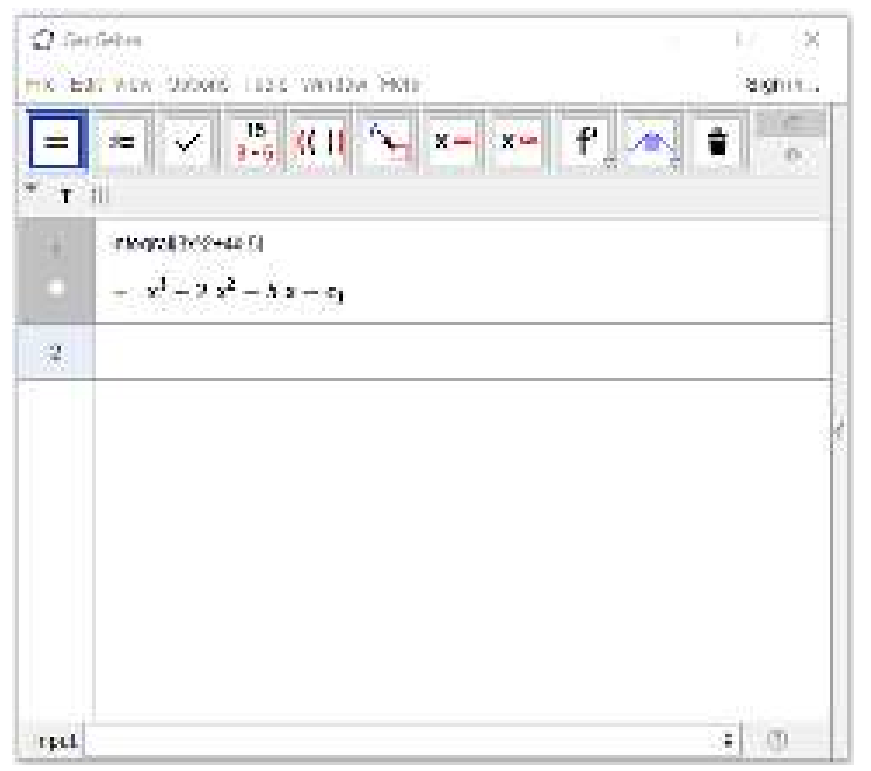

Gambar 1. Integral Tak Tentu

Tahapannya sebagai berikut: Pertama Klik view masuk pada tampilan CAS, kemudian pada bilah masukan baris 1 , ketikan integral[3 $\left.3 x^{\wedge} 2+4 x-5\right]$ lalu tekan enter, maka akan tampil hasil dari integral $\left(3 x^{2}+4 x-5\right) d x$ yaitu $x^{3}+2 x^{2}-5 x+c_{1}$ 
Histogram: Jurnal Pendidikan Matematika, 4 (2), 2020 - 596

Amiruddin', Esterina Natalia Paindan²

2. Menentukan integral tentu dari suatu fungsi

Contoh : Tentukan nilai dari $\int_{1}^{2}\left(3 x^{2}+4 x-5\right) d x$. Maka penggunaanya dengan geogebra tampak pada gambar berikut ini

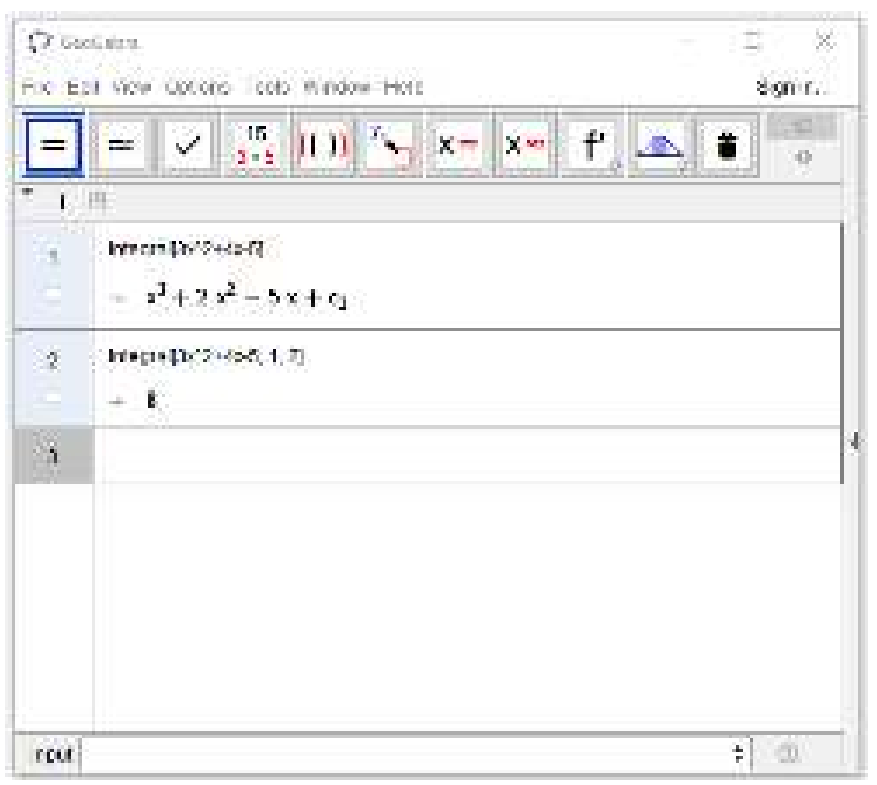

Gambar 2. Integral Tentu

Tahapannya sebagai berikut: Pada bilah masukan baris 2 , ketikan integral[ $3 x^{\wedge} 2+4 x-$ $5,1,2]$ lalu tekan enter, maka akan tampil hasil dari integral $\left(3 x^{2}+4 x-5\right) d x$ dengan batas bawah adalah 1 dan batas atas adalah 2 diperoleh nilai dari integral tentu tersebut adalah 8

3. Menentukan luas daerah yang dibatasi sebuah kurva

Contoh : Tentukan luas daerah yang dibatasi kurva $f(x)=x^{2}$ pada selang 1 dan 2 diatas sumbu-x . Maka penggunaanya dengan geogebra tampak pada gambar berikut ini 
Histogram: Jurnal Pendidikan Matematika, 4 (2), 2020 - 597 Amiruddin', Esterina Natalia Paindan²

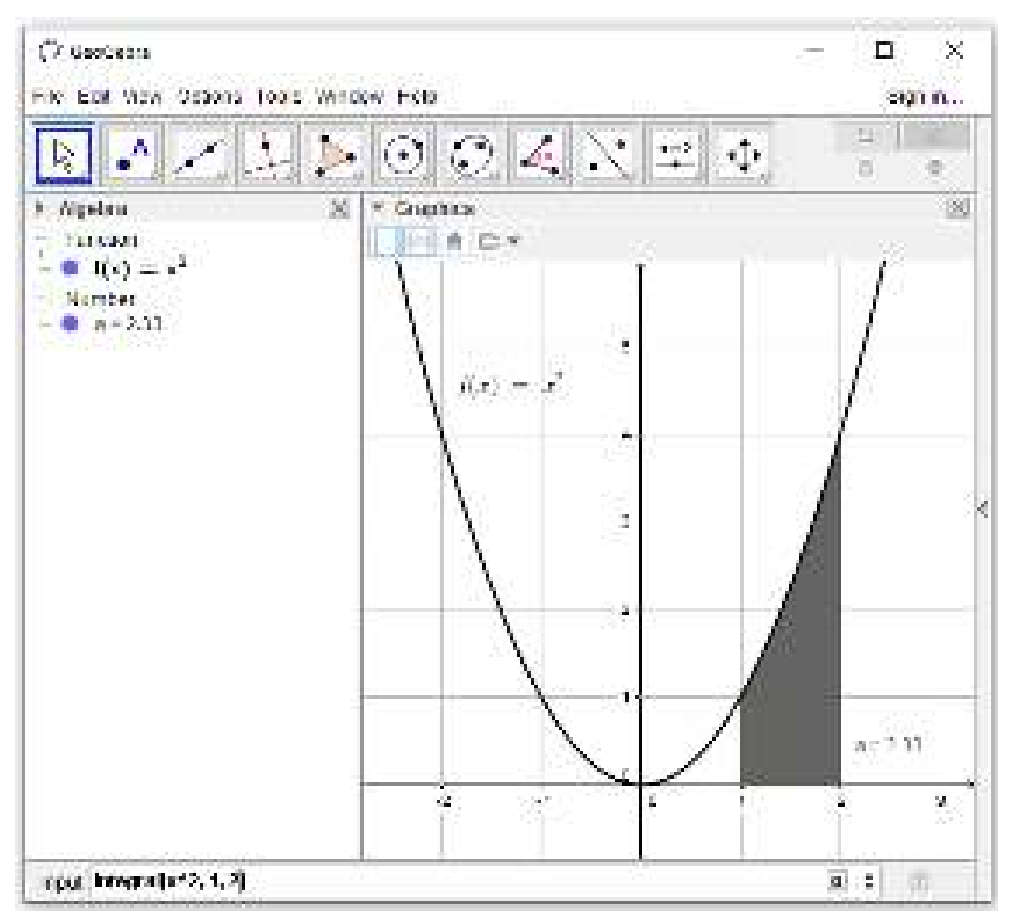

Gambar 3. Luas daerah yang dibatas sebuah kurva

Tahapannya sebagai berikut: Pertama Klik view masuk pada tampilan Grapichs, kemudian pada bilah input, ketikan fungsiya $\mathrm{f}(\mathrm{x})=\mathrm{x}^{\wedge} 2$ lalu tekan enter, kemudian untuk menentukan luas daerahnya, ketikan pada bilah input integral $\left[\mathrm{x}^{\wedge} 2,1,2\right]$ lalu tekan enter, sehingga nampak luas daerah yang dimaksud pada interval 1 sampai 2 dengan luasnya adalah 2.33

4. Menentukan luas daerah diantara dua kurva

Contoh : Tentukan luas daerah yang dibatasi kurva $f(x)=x^{2}$ dan $g(x)=2 x$. Maka penggunaanya dengan geogebra tampak pada gambar berikut ini 
Histogram: Jurnal Pendidikan Matematika, 4 (2), 2020 - 598

Amiruddin', Esterina Natalia Paindan²

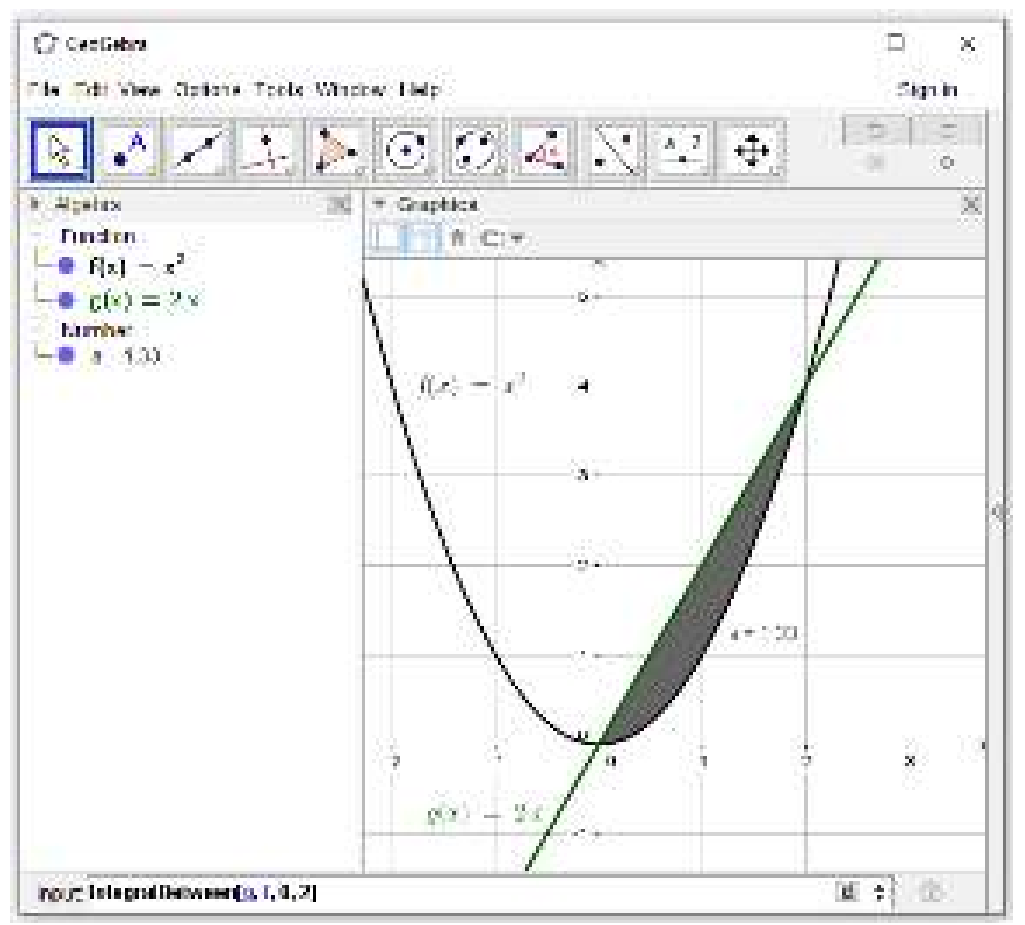

Gambar 4. Luas daerah yang dibatas dua kurva

Tahapannya sebagai berikut: Pertama Klik view masuk pada tampilan Grapich kemudian pada bilah input, ketikan fungsi pertama $\mathrm{f}(\mathrm{x})=\mathrm{x}^{\wedge} 2$ lalu tekan enter, kemudian untuk fungsi kedua $\mathrm{g}(\mathrm{x})=2 \mathrm{x}$ lalu tekan enter, kemudian untuk menentukan luas daerah yang dibatasi kedua kurva tersebut, ketikan pada bilah input integralbetween[g,f,0,2] lalu tekan enter, sehingga nampak luas daerah yang dibatasi oleh dua kurva $x^{2}$ dan $2 x$ adalah 1.33

Berdasarkan hasil penelitian penggunaan geogebra yang dilakukan pada mahasiswa untuk melihat peningkatan kemampuan pemahaman matematis diperoleh informasi dari hasil pretest nilai terendah adalah 20 dan nilai tertinggi adalah 80 dari skor idealnya 100. Hal ini menujukkan bahwa kemampuan pemahaman matematis siswa sangat rendah, padahal saat jenjang SMA/SMK sebelum masuk perguruan tinggi, mahasiswa telah belajar materi tentang integral. Berdasarkan pengamatan peneliti bahwa rendahnya kemampuan pemahaman matematis mahasiswa disebabkan oleh waktu libur yang panjang sehingga mahasiswa lupa akan materi yang telah mereka pelajari, dilain hal mahasiswa juga menjelaskan bahwa saat penjelasan materi di SMA/SMK mahasiswa terkadang merasa bosan dengan pola pembelajaran yang diterapkan guru di kelas.

Pada saat mahasiswa diberi perlakuan dengan menggunakan software geogebra dalam memahami materi integral, mahasiswa terlihat aktif, senang dan antusias sekali, 


\section{Histogram: Jurnal Pendidikan Matematika, 4 (2), 2020 - 599 Amiruddin' $^{1}$, Esterina Natalia Paindan ${ }^{2}$}

semua mahasiswa menggunakan gadget smartphone mereka yang telah terinstall aplikasi geogebra. Berdasarkan hasil postest diperoleh nilai terendah adalah 40 dan nilai tertinggi adalah 100 dari skor ideal 100, dan berdasarkan nilai rata-rata terjadi kenaikan 35.83 dari nilai rata-rata pretest sebesar 38,33 menjadi nilai rata-rata postets sebesar 74,17 , dengan simpangan baku pre test sebesar 18,89 dan simpangan baku postest sebesar 15,38, hal ini menunjukkan bahwa sebaran data untuk nilai post test mendekati nilai rata-rata 74,17 . Skor $\mathrm{N}$-Gain ternormalisasi diperoleh nilai sebesar 0,62 dan dengan simpanga baku 0,20 , hal ini menunjukkan bahwa kemampuan pemahaman matematis mahasiswa dengan menggunakan software geogebra dalam pembelajaran materi integral meningkat. Skor peningkatan ini berdasarkan N-Gain sebesar 0,62 dengan kategori sedang, adapun untuk tafisaran kefektifan sebesar $62 \%$ dengan kategori cukup efektif. Sehingga dapat disimpulkan bahwa penggunaan software geogebra untuk materi integral pada matakuliah matematika I dapat meningkatkan pemahaman matematis mahasiswa.

\section{KESIMPULAN DAN SARAN}

\section{A. Kesimpulan}

Berdasarkan rumusan masalah, hasil penelitian dan pembahasan seperti yang telah dikemukakan pada bab sebelumnya, diperoleh kesimpulan bahwa penggunaan software geogebra untuk materi integral pada matakuliah matematika I dapat meningkatkan kemampuan pemhaman matematis mahasiswa.

\section{B. Saran}

Berdasarkan kesimpulan di atas, maka peneliti menyarankan agar penggunaan geogebara tidak hanya diterapkan pada materi integral saja melainkan dapat menerapkan ke materi matematika lainnya, selanjutnya pada materi integral dapat dilakukan pengembangan dengan mendalami fitur-fitur yang tersedia pada software geogebra, misalnya untuk pendalaman materi volume benda putar, integral lipat, integral-integral lainnya serta aplikasinya pada matakuliah matematika II.

\section{DAFTAR PUSTAKA}

Hikmah, R. (2017). Penerapan Model Advance Organizer untuk Meningkatkan Kemampuan Pemahaman Siswa. SAP (Susunan Artikel Pendidikan), 1(3), 271-280. https://doi.org/10.30998/sap.v1i3.1204

Nur, I. M. (2016). Pemanfaatan Program Geogebra dalam Pembelajaran Matematika. Jurnal 
Histogram: Jurnal Pendidikan Matematika, 4 (2), 2020 - 600

Amiruddin', Esterina Natalia Paindan²

https://doi.org/10.1038/oncsis.2016.1

Putra, H. D., Setiawan, H., Nurdianti, D., Retta, I., \& Desi, A. (2018). Kemampuan Pemahaman Matematis Siswa Smp Di Bandung Barat. Jurnal Penelitian Dan Pembelajaran Matematika, 11(1). https://doi.org/10.30870/jppm.v11i1.2981

Sari, D. P., Nurochmah, N., Haryadi, H., \& Syaiturjim, S. (2016). Meningkatkan Kemampuan Pemahaman Matematis Melalui Pendekatan Pembelajaran Student Teams Achivement Division. Jurnal Riset Pendidikan Matematika, 3(1), 16. https://doi.org/10.21831/jrpm.v3i1.7547

Siagian, M. V. (2020). Kemampuan Mahasiswa dalam Memecahkan Masalah Grup Berdasarkan Langkah Polya Ditinjau dari Gender. Algebra: Journal of Mathematics Educatioan and Science, 1(1), 12-15.

Sugiyono. (2011). Metode penelitian pendidikan: pendekatan kuantitatif, kualitatif, dan $R \& D$. Alfabeta.

Syarifah, L. L. (2017). Analisis Kemampuan Pemahaman Matematis Pada Mata Kuliah Pembelajaran Matematika Sma Ii. Jurnal Penelitian Dan Pembelajaran Matematika, 10(2), 57-71. https://doi.org/10.30870/jppm.v10i2.2031

Tanzimah. (2019). Pemanfaatan Software Geogebra Dalam Pembelajaran Matematika. Prosiding Seminar Nasional Pendidikan Program Pascasarjana Universitas PGRI Palembang 03 Mei 2019. https://doi.org/10.19109/jpmrafa.v3i1.1441

Yensy, N. A. (2020). Efektifitas Pembelajaran Statistika Matematika melalui Media Whatsapp Group Ditinjau dari Hasil Belajar Mahasiswa (Masa Pandemik Covid 19). Jurnal Pendidikan Matematika Raflesia, 05(02), 65-74. 